\title{
Work, Family and School - Balanced Postgraduate Programs for Full-Time Workers in Finland
}

\author{
https://doi.org/10.3991/ijac.v12i3.11254 \\ Matti Koivisto \\ South-Eastern Finland University of Applied Sciences, Mikkeli, Finland \\ matti.koivisto@xamk.fi
}

\begin{abstract}
Today employees have to update their knowledge, skills and competencies to excel in the working world. Therefore, the number of adult students has increased in all forms and levels of education including universities. Adult students bring non-traditional characteristics to campuses including part-time enrollment, full-time employment, and increased family obligations. In this paper, an analytical model for analyzing different roles of professionals returning to university is developed. The model is then applied to describe the current support systems for adult learners in Finland and to analyze a Finnish postgraduate program solely targeted for professionals returning to college. The findings of the study suggest that programs dedicated to adult learners help returning students to find a better balance between their work, family and school roles and thus overcome more easily the institutional, situational and dispositional barriers to study.
\end{abstract}

Keywords-Adult education, postgraduate degrees, conflict, life balance

\section{Introduction}

Learning new skills is important for surviving in the current rapidly changing world of work. Luckily, we currently have a large number of alternatives to increase our professional competence. Video sharing services, professional certification programs, educational institutions and many others offer us huge possibilities to learn. However, many professionals find great difficulties in fitting learning and studying into their busy lives. Requirements of lifelong learning do not challenge only individuals but also institutions like colleges and universities. Therefore, they have to think beyond the traditional ways of delivering education to fulfill better needs and expectations of their potential students.

The aim of the study is to gain a better understanding about roles and conflicts faced by working professionals returning to college and how higher-level institutions can help adult learners to overcome these barriers to study. The empirical part of the study analyzes student perceptions on the topics pointed out in the theory part of the paper. The subjects of the study are adult master's degree students of a Finnish university of applied sciences. 
In Finland, the Universities of Applied Sciences (UASs) aim all their master programs for working professionals. All postgraduate programs offered by the UASs require at least three years of work experience after the undergraduate degree and they have strong focus on life balance, the effective use of online and e-learning methods, and connecting study tasks to workplace problems and challenges.

The structure of the paper is as follows. Chapter 2 contains a short literature review focusing on different roles of full-time working professionals returning to college and their obstacles to study. The outcome of the discussion is a life balance model, which combines the findings of the role conflict theory and the variables influencing learning of adults working full time. Chapter 3 shortly describes the Finnish higher education system and national support mechanisms for adult learners. Chapter 4 is the empirical part of the study. It first introduces the postgraduate program used in the study and then describes the design and results of the survey conducted among the students of the program. The topics of the survey are extrinsic and intrinsic motivation, obstacles of study, different stakeholders' support as well as students' perception on the implementation of the program. Finally, Chapter 5 provides a few concluding thought and suggestions for further study.

\section{Roles of Working Students and Their Obstacles to Study}

All of us have a number of social roles and these roles affect our lives [1]. A role contains a set of responsibilities, requirements and attitudes to others [2]. Frone [3] divided the primary social roles of an adult into two main categories: work and nonwork domain as shown in Figure 1.

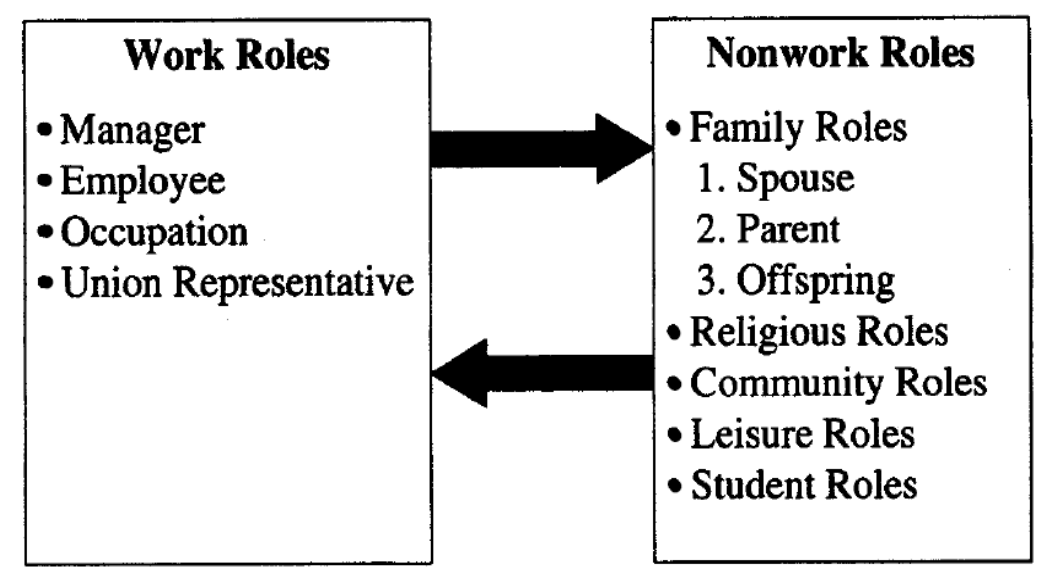

Fig. 1. Work and non-work roles [3]

Working professionals returning to college have a number of different roles, and according to role conflict theory, demands from different domains compete with each other in terms of time and energy [4]. Scholars often call it a Work-School Conflict 
(WSC) (e.g. [5], [6]). To understand better the WSC I will next focus on variables influencing learning of working adults and then analyze the essential barriers of adult learning.

\subsection{Variables influencing learning}

During recent decades, several theoretical frameworks for adult learning have been created to help researchers and practitioners to find new adult education methods. Some examples of the frameworks are widely debated andragogy [7], self-directed learning [8] and transformative learning [9]. Although the theories naturally have their differences, they all more or less share the following ideas. Mature learners have a wide variety of experiences that influence both their motivation and expectations. They want to share and discuss their own experiences and learn from their peers. The content of studies must have relevancy back at the workplace. Above all, they do not want to waste their valuable time and therefore learning methods should be efficient and effective.

O'Connor and Cordova [10] identified in their study variables influencing learning of working adult students who return to the university part-time for advanced professional degrees. Their model consists of the following three variables: individual characteristics, the work and the learning environment. From the conflict theory's point of view, the places where these three variables overlap are especially interesting. The intersections are personal relevance between individual characteristics and learning environment, job involvement between individual characteristics and work environment and content relevance between learning and organizational environment.

\subsection{Obstacles to study}

Scholars have listed a number of obstacles preventing adults from returning to college. Many of these obstacles are not present only when potential students evaluate their possibilities to return to school but also during their whole study time. Most often mentioned barriers are time and money. For more details please see [11] and [12]. In this study, the following three categories of barriers of adult learners are used [13]:

- Institutional barriers: Practices that discourage working professionals from participating in educational activities such as inconvenient schedules, locations, and tuition fees.

- Situational barriers: Issues related to the adult student's current life such as job and home responsibilities.

- Dispositional barriers: Topics related to attitudes and self-perceptions about the adult student as a learner.

\subsection{Life balance model for adult learners}

Adult learners returning to college must find a balance between their different roles and combine these roles in a relevant way to overcome their obstacles to study. Based 
on earlier discussion a life balance model for adult learners is created and it is shown in Figure 2 below.

The model has its roots in the role conflict theory suggesting that adult learners have to combine their individual life both with work and student roles. If these roles fit well together (for example studies have relevance both from personal and job perspectives), a student would find it easier to share time between them and to fulfill responsibilities associated with each of them. On the other hand, adult learners interact with a number of stakeholders, including but not limited to family and friends, other students, employers, universities and society as a whole. The stakeholders' support or resistance affect how easily a working professional is able to overcome the dispositional, institutional and situational barriers to study and find a balance between different dimensions of his or her life.

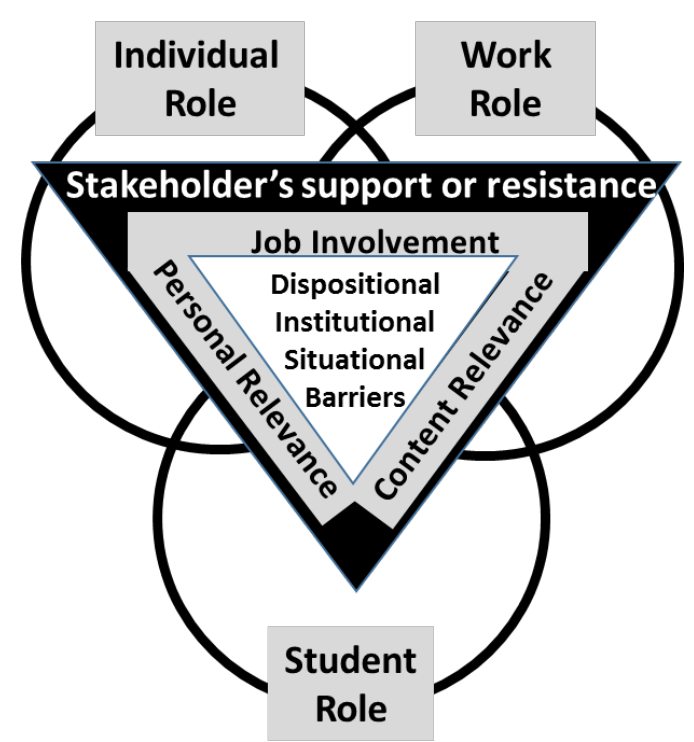

Fig. 2. Life-balance model for adult learners.

\section{Higher Education for Adult Learners in Finland}

The Finnish higher education system consists of universities and Universities of Applied Sciences (UASs). The difference between them is as follows. Universities focus on scientific research and education based on it. UASs offer a more practical education responding to working life needs. In addition, the focus of UASs research and development (R\&D) activities is not on basic but on applied R\&D [14]. Both types of higher education institutions offer undergraduate and graduate programs. The special characteristic of the UAS master programs is that they are targeted to people with years of work experience. Students can apply to a master's program organized by a UAS only 
if they have at least three years of work experience after gaining an undergraduate degree [15]. Master programs organized by the Finnish universities do not have this requirement.

\subsection{Support mechanisms for adult learners in Finland}

As pointed out earlier returning students face institutional, situational and dispositional barriers to study. This section presents the national policies to support adult learners in Finland. These policies pay special attention to two major areas: money and time.

In Finland, there are two major financial adult education enablers. First, the education in Finland is free at all levels. According to law, higher education institutions cannot charge tuition fees for a degree. This rule applies to all Finns and students coming from some other European Union countries [15], [16]. Second, the government has created a special support system for adult learners called Adult Education Allowance. The allowance supports adults to develop their professional abilities and to update their skills and knowledge. Applicants must fulfill the following two conditions of eligibility. First, they must have at least eight years of employment history and second they must study full time. [17] The amount of the allowance depends on your salary and Table 1 shows some examples. The numbers are in U.S. dollars to serve the audience of the paper better.

Table 1. Examples of the annual adult study allowances based on annual income

\begin{tabular}{|c|c|c|}
\hline Pre-tax annual income (USD) & $\begin{array}{c}\text { Pre-tax annual allowance } \\
\text { (USD) }\end{array}$ & Difference \\
\hline 25000 & 15000 & $-40 \%$ \\
\hline 50000 & 24000 & $-52 \%$ \\
\hline 75000 & 29000 & $-61 \%$ \\
\hline 100000 & 33500 & $-67 \%$ \\
\hline
\end{tabular}

Figure 3 shows the number of people receiving the adult education allowance in 2010 - 2018. The popularity of the allowance has increased steadily over the years. In 2016, the government made some changes to the terms of the allowance and that has at least temporarily slowed down growth. According to the latest reports, more than 60 per cent of people receiving the allowance are from 30 to 44 years old. Also, more than two-thirds of the receivers are studying in a new discipline, most typically in the field of social and health care [18]. 


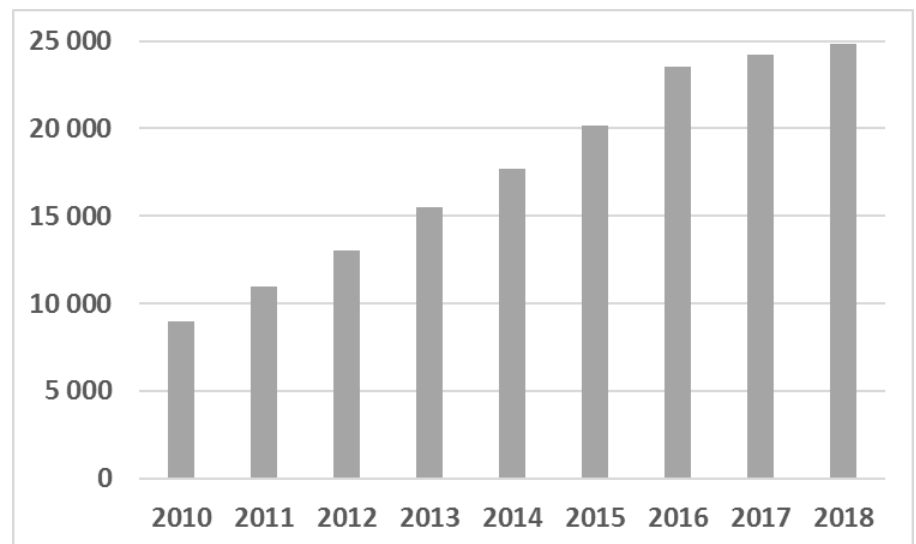

Fig. 3. The number of the adult education allowance receivers [17].

To overcome the second obstacle, finding time to study, Finland has enacted Study Leave Law. It allows an employee to take sabbatical for further education. The details of the law are beyond the scope of the paper, but in general an employee who has worked at least one year for the same employer can take up to two years unpaid time off to study. The employer must accept the employee's study application. However, if the study leave of an employee is expected to create serious challenges to the company, the employer can postpone the leave for 12 months. [19]

\section{Study on Postgraduate Program for Full-Time Working Engineers}

The empirical part of the study focuses on a Master of Science program in Project and sales management. As mentioned earlier, this program is targeted for working professionals returning to college. The UAS responsible for the program has made the following three decisions of minimizing the institutional barriers faced by the students. First, the program uses a blended learning method, which combines both online and traditional learning. This limits the amount of time spent in the classrooms. Second, all lectures are organized outside the office hours (on Saturdays or on weekday evenings). This allows students to work full time if they decide to do so. Third, two student groups meet at the same time in two different cities (Kotka and Mikkeli) located about 100 miles from each other. This arrangement reduces students' travel time because they can select a location based on their individual needs. However, it is worth pointing out that although students are in two location there is only one teacher. The teacher travels between two locations so that he is every second time in one city and next time in the other one. The classrooms have a video connection between them and all students use their own computers because the program applies a Bring Your Own Device (BYOD) policy. 


\subsection{Study design}

The aim of the study is to find out how well the current students have been able to find a balance between their different roles. Because this is a new program, the UAS also wants to find out students' perceptions on the decision to use blended learning instead of a full online approach. The decision was based on the idea of peer learning. In peer learning, students interact with other students to attain their educational goals [20]. The UAS expected that peer learning would suit this program extremely well because every student has a lot of experience in their field of study after gaining their bachelor's degree in engineering. Their experiences and different backgrounds allow them to benchmark their own methods and systems against the experiences of their fellow students.

To reach the aims of the study I carried out a small-scale survey. The number of students taking part in the survey was 42, and 19 of them studied mainly in Mikkeli and 23 in Kotka. The average work experience of the subjects (after the bachelor's degree) varied between 3 and 25 years (mean=11.6, standard deviation $(S D)=5.2$ ). The average age of a student was 40.8 years as the youngest student was 28 and the oldest 56 years old. Only two students were on a study leave and both of them received the adult education allowance. The rest of the students worked full time.

The survey was conducted in Finnish. It followed the model introduced in Section 2 and it focused on the following areas: intrinsic and extrinsic motivation to start postgraduate studies, barriers to study, stakeholders' support, and the implementation method of a master's program (blended learning vs. fully online). The questionnaire used a Likert scale from one to five.

\subsection{Results}

According to the results, the students of the program have a very high intrinsic motivation (mean $=4.70, \mathrm{SD}=.51)$ and quite high but significantly lower $(\mathrm{p}=.05)$ extrinsic motivation (mean=3.88, $\mathrm{SD}=1.20$ ). Thus, the results suggest that the main purpose to study was to learn new skills and knowledge instead of gaining a higher degree.

The results suggest that students had a very high trust on their capabilities to complete their studies and study arrangements seem to fit their needs. Therefore, both dispositional and institutional barriers were significantly lower $(p=.05)$ than situational barriers (see Table 2 for more details). Although the situational barriers are the most relevant obstacle to study among the students of the program, the results suggest that most of the participants (71.4 per cent) have been able to find a good or very good balance between studies, work and other aspects of life. It is worth mentioning that overall, 46 students started in the program and four of them have dropped out. These four did not take part in the survey but they were interviewed separately. All of them pointed out that their reasons to quit were related to the situational barriers (lack of time and challenges to fit studies to their work responsibilities). Therefore, a more accurate share of students with a self-reported high level of life balance is 65.2 per cent.

The students' responses also highlighted that stakeholders' support is an important factor for studying adults. The participants think that they received most support from 
other students (mean=4.40) and family and friends (mean=4.31). Support from the employers was also quite high but still significantly lower (mean=3.81, $\mathrm{p}=.05$ ). See Table 2 for more details. As mentioned earlier, only two students applied the support systems provided by the government (the study leaves and the study allowance). Therefore, the support from the government did not play an important role for most of the students in this program excluding the free education.

According to O'Shea, et al. [21] online delivery reduces many of the barriers associated with attending university [22]. Other scholars (e.g. [22] and [23]) have the highlighted advantages of e-learning especially to adult learners. Participants of the survey, however, gave a strong support for blended learning. The huge majority of students (92.9 per cent) disagreed or strongly disagreed with a statement that the program could be implemented fully online. The selected learning method was also supported by the high attendance rates of the face-to-face sessions (higher than 95 per cent).

Table 2. Main results of the survey.

\begin{tabular}{|c|c|c|}
\hline \multicolumn{3}{|c|}{ Motivation } \\
\hline & Mean & $S D$ \\
\hline Intrinsic motivation & 4.70 & 0.51 \\
\hline Extrinsic motivation & 3.88 & 1.20 \\
\hline \multicolumn{3}{|c|}{ Barriers to study } \\
\hline & Mean & $S D$ \\
\hline Dispositional barriers & 1.57 & 0.76 \\
\hline Institutional barriers & 1.52 & 0.55 \\
\hline Situational barriers & 2.21 & 1.01 \\
\hline \multicolumn{3}{|c|}{ Support from stakeholders } \\
\hline & Mean & $S D$ \\
\hline Support from work & 3.81 & 1.01 \\
\hline Support from family and friends & 4.31 & 0.83 \\
\hline Support from other students & 4.40 & 0.66 \\
\hline
\end{tabular}

\section{Conclusion}

In the rapidly changing world, the number of the adult learners is rising and therefore higher education institutions should not treat them any more as special cases or nontraditional students. Instead, universities should put more effort into meeting the expectations and needs of the adult students.

The findings of the study confirm that adult learners have a number of different roles and to succeed in their studies they must find a balance between work, family, and school lives. The results indicate that programs specially targeted for adult learners help them to overcome their barriers to study. The results also suggest that students find situational barriers more severe than dispositional and institutional barriers. However, it is important to bear in mind that the survey was carried out only among adults who have already returned to college. People who have not made the same decision yet might find dispositional and institutional barriers more relevant to them. I need to strongly state that this idea requires further study. 
Although online learning has many advantages, the large majority of the participants preferred blended learning to online learning. Students seem to value highly the possibility to learn from their peers. The role of the other students was not only limited to learning but students also think that they received a lot of support from their peers during the face-to-face sessions.

The findings of this study point out that only a small number of students decides to study full time and take temporary leave from work. Possible reasons could include large differences between the salary and allowance, employers' attitudes and students own beliefs about how a temporary leave could affect their careers. However, further studies are still needed before any conclusions can be made.

\section{$6 \quad$ References}

[1] Clark, S. (2000). Work/family border theory: A new theory of work/family balance. Human Relations, 53: 747-770 https://doi.org/10.1177/0018726700536001

[2] Xinjia, Y., Chunyan, M., Leung, C. and Salmon, C.T. (2017). Role conflict and ambivalence in the aged-parent-adult-child relationship. International Journal of Crowd Science, 1(2): 161-170 https://doi.org/10.1108/IJCS-08-2017-0012

[3] Frone, M.R. (2003). Work-Family Balance in Handbook of Occupational Health Psychology ed. Quick, J.C. and Tetric, L.E. Washington D.C.: American Psychological Association, 143-162 https://doi.org/10.1037/10474-007

[4] Greenhaus, J.H. and Beutell, N.J. (1985). Sources of conflict between work and family roles. Academy of Management Review, 10(1): 76-88 https://doi.org/10.5465/amr.1985.4277352

[5] Markel, K.S., and Frone, M.R. (1998). Job characteristics, work-school conflict, and school outcomes among adolescents: Testing a structural model. Journal of Applied Psychology, 83(2): 277-287 https://doi.org/10.1037/0021-9010.83.2.277

[6] Cinamon, R.G. (2018). Navigating work and study: Antecedents and outcomes of conflict and facilitation aspects of the work-school interface. Journal of Vocational Behavior. 104: 31-43 https://doi.org/10.1016/j.jvb.2017.09.009

[7] Knowles, M.S. (1980) The Modern Practice of Adult Education: From Pedagogy to Andragogy. $2^{\text {nd }}$ ed. New York: Cambridge Books.

[8] Grow, G. (1991). Teaching Learners to Be Self-Directed: A Stage Approach.” Adult Education Quarterly, 44(2): 109-114 https://doi.org/10.1177/074171369404400206

[9] Mezirow, J.D. and Associates. (2000). Learning as Transformation: Critical Perspectives on a Theory in Progress. San Francisco, CA.

[10] O'Connor, B.N. and Cordova, R. (2010). Learning: The Experiences of Adults Who Work Full-Time While Attending Graduate School Part-Time. Journal of Education for Business, 85: 359-368 https://doi.org/10.1080/08832320903449618

[11] Ross-Gordon, J. (2011). Research on Adult Learners: Supporting the Needs of a Student Population that Is No Longer Nontraditional. PeerReview, 13(1)

[12] Burke, K. (2016). Assessing Adult Learner Experience at Northern Stark University: An Exploratory Study. Education Student Publications. Merrimack College.

[13] Cross, K.P. (1981). Adults as learners: Increasing participation and facilitating learning. San Francisco, CA: Jossey-Bass.

[14] Ministry of Education. (2018). Higher education institutions, science agencies, research institutes and other public research organizations. Retrieved from http://minedu.fi/en/heisand-science-agencies 
[15] The Law on Universities of Applied Sciences. (in Finnish), 14.11.2014/932.

[16] The Law on Universities. (in Finnish), 24.7.2009/558.

[17] Employment Fund. (2019). Benefits for Adult Students. Retrieved from https://www.tyolli syysrahasto.fi/en/

[18] STT. (2019). The number of people receiving adult education allowance increases, (in Finnish), YLE, March $3^{\text {rd }}, 2019$.

[19] The Study Leave Law. (in Finnish), 9.3.1979/273.

[20] O’Donnell, A.M. and King, A. (1999). Cognitive perspectives on peer learning, Mahwah, NJ: Lawrence Erlbaum.

[21] O'Shea, S., Stone, C. and Delahunty, J. (2015). I 'feel' like I am at university even though I am online. Exploring how students narrate their engagement with higher education institutions in an online learning environment. Distance Education, 36(1): 41-58 https://doi.org/10.1080/01587919.2015.1019970

[22] Chong, G., Ding, D. and Kong, W.H. (2015). E-Learning in Higher Education for Adult Learners in Singapore. International Journal of Information and Education Technology, 5(5): 348-353 https://doi.org/10.7763/IJIET.2015.V5.528

[23] Cercone, K. (2008). Characteristics of adult learners with implications for online learning design. AACE Journal, 16(2): 137-159

\section{$7 \quad$ Author}

Matti Koivisto is an engineering educator and principal lecturer at South-Eastern Finland University of Applied Sciences (XAMK), in Mikkeli, Finland. He holds a doctoral degree from Helsinki University of Technology, Finland.

This article is a revised version of a paper presented at the International Conference on E-Learning in the Workplace 2019 (ICELW 2019), held in June 2019, at Columbia University in New York, NY, USA. Article submitted 2019-07-11. Resubmitted 2019-08-21. Final acceptance 2019-08-22. Final version published as submitted by the authors. 